\title{
PROBLEMATIKA SAOPŠTAVANJA NEKIH KNJIŽEVNIH POJMOVA U ITALIJANSKIM ENCIKLOPEDIJSKIM REČNICIMA
}

Enciklopedijski rečnik u jednoj svesci pored toga što je praktičan može biti i vrlo koristan, tj. izvanredan je posrednik mnogostruke tematike koju saopštava na više manje koncizan način.

Dve do tri hiljade stranica zbijenih, sitnih redova otkrivaju upečatljive pojedinosti iz bilo koje oblasti, tj. pružaju prvo neophodne osnovne priloge. Već u samom osnovnom prilogu saopštenja mogu biti dovoljno informativna, dovoljno iscrpna a često i sasvim zadovoljavajuća. U većini slučajeva odatle se mogu iscrpsti mnoge pojedinosti, čak i sa obiljem podataka, kao i definicije raznih pojmova, a često osnovni prilog može dovoljno da odredi ili potvrdi i koncepciju bilo koje tematike. Može da pruži i potrebnu preciznost možda kog vremenskog perioda, vrste roda, osobinu značenja i u prenosnom smislu, ili koju etimološ$\mathrm{ku}$, istorijsku, umetničku, literarnu itd. funkciju datog pojma. Prema tome, uglavnom, i cenimo pravi izraz mere u kojoj se sistematičnost, kao glavna osobina enciklopedijskih saopštenja, pozitivno odražava. Medjutim, o efikasnosti i zadovoljavajućoj doslednosti materijala koji crpemo, razume se, možemo suditi u onom obimu do kojeg doseže poznavanje razvojne linije delatnosti koju pratimo. Bilo delimična ili iscrpnija obaveštenja koja nam pruža osnovni prilog najčešće služe samo kao putokaz ka saopštenjima potpunije razmere, i baš od tog uputa u tok kontinuiteta našeg istraživanja zavisi efikasnost materijala koji crpemo.

Bilo bi vrlo važno a ponekad i nužno da nam takav enciklopedijski rečnik pruži, naročito ako je nedovoljno saopštenje u osnovnom prilogu, i izvestan kontinuitet u niti materijala koji nam saopštava preko srodnog ili proširenog priloga, preko direktnih odrednica ili odgovarajućih uputa, ili najidealnije preko neoznačenih odrednica koje sasvim spontano proizilaze iz teksta ili koncepcije osnovnog priloga. To je neobično korisno za sve oblasti o kojima bismo u nekom od takvih proširenih rečnika potražili obaveštenja (naročito za neke istorijske pojave, istorijska zbivanja, pri čemu se često može pratiti i geneološka loza ličnosti, vremenski periodi $i$ sl., smene literarnih perioda, književnih pravaca i mnogih drugih književnih i umetničkih pojava i kretanja).

Obično očekujemo da nam osnovni prilog iscrpi najvažnije podatke, da nam sistematski prikaže suštinu, obim ili definiciju traženog pojma. Ako to nije slučaj, posežemo za dopunskim elementima po liniji srodnog razvoja, po izvesnom prenosnom mehanizmu ili kontinuiranom saopštavanju koje je često sasvim dostupno u nekim takvim rečnicima. Ako takva dopunska saopštenja ne postoje i ne uspemo da iscrpemo ono najvažnije za pravi izgled pojma, izraza odnosno teme za kojom tragamo, onda je jasno da moramo (a ponekad i za najobičnija i najjednostavnija obaveštenja) pribeçi iscrpnijim izvorima, enciklopedijama itd. 
Danas se sve više primećuje da nije dovoljna samo sistematizacija enciklopedijskog materijala u alfabetske serije, već i prikazi i strukture raznovrsnih funkcija što se uglavnom omogućava praćenjem prenosne linije povezivanja srodnih pojmova. Pri tome bi mnoštvo elemenata, tematski srodnih i svrstanih u odgovarajuće alfabetske grupacije, moglo pružiti potpuniji materijal za okvirni izgled teme, razume se samo teme koju stručnjak može pratiti. Dakle, takav enciklopedijski rečnik, pružio bi nam, da tako kažemo, izvesnu kontinuiranu azbučno predmetnu tematsku liniju.

Ekspertima i saradnicima koji uglavnom tako i posmatraju ono što nam iz raznih disciplina saopštavaju, očigledno je namera da, što je moguće više, iscrpu neophodne elemente iskazane u nužnoj konciznosti, ali tako da sva sažimanja (uslovljena nivoom, veličinom i namenom rečnika) koncepciono sadrže što više vernih izraza i situacija iz adekvatne, stručne, originalne odnosno namenske literature.

Sasvim je zadovoljavajuće ako se iz tih proširenih rečnika može izvući i jedna tematska nit, ako se može nazreti izvestan tok koji vodi ka iscrpnosti materijala potrebnog za praćenje $i$ dopunjavanje teme. A sve to je najčešće u zavisnosti ne toliko od obima koliko od samog vida rečnika, informativnog ili tematskog."

Ako je rečnik potpunije enciklopedijski, ne samo striktno informativnog već i koncepcionog vida, tj. ako nam pored osnovnog priloga pruža i moguénosti proširene dopune materijala, onda nam daje i tematska saopštenja u skladnoj povezanosti srodnih elemenata (naročito preko odrednica za kontinuirani prenos) i time uslovljava celinu logično povezanog teksta.

Te odrednice za prenosna šira objašnjenja valja da su dosledno povezane, što je upravo i najteže, a naročito $u$ istorijskom i književnom smislu, gde sistematičnost opisnih situacija teško prijanja mnogim ograničenjima i isključivosti definisanja završno zaključnih perioda.

Tako bi nam neki primeri iz književne namene ili termini bliski književnom smislu, možda bili korisni kao ilustracija pomenutih vidova takvih saopštenja u italijanskim rečnicima.

Potražili smo tako izraz -kanovačo (canovaccio, canevaccio) - ne u njegovoj etimološkoj funkciji, niti u značenju svojstvenom praktičnoj nameni, već u literarnom smislu. Tu bismo hteli saznati koja saopštenja možemo dobiti iz osnovnog priloga u pogledu koji nas interesuje, ili postoje mogućnosti za izvesne dopune elemenata koji bi nam dali obrazloženiju celinu traženog pojma. Dakle, pravi smisao bi, kao i kod svih drugih pojmova, bio ili samo nagovešten ili sasvim predstavljen $i$ definisan odmah $u$ osnovnom prilogu, ili razjašnjen preko odrednica za dopunu u srodnim proširenim prilozima. Procedura takvog saopštavanja u najvećem broju slučajeva nije jednostavna, jer ukoliko nije postignuta pravilna linija povezivanja, izvestan važan kontinuitet, taj smisao se može preinačiti illi potpuno izgubiti. 
Naš primer kanovačo (okosnica), kao važan elemenat komedije dell'arte, bio bi saopšten i u tom svojstvu, i to kao uži pojam - u osnovnom prilogu, i, kao širi pojam - u proširenom prilogu, dakle pri elementima saopštenja u komediji (del l'arte).Medjutim, pri prenošenju indikacija na širi pojam saopštenje se može ili upotpuniti ili toliko osiromašiti da se često izgubi čak i bitna nit osnovnog priloga.

Ako u osnovnom prilogu za kanovačo stoji - "Schema o sommario di un opera. Traccia scritta di un azione scenica. Commedia d'arte (a soggetto) V. commedia". I - nisu pravilno iscrpljeni, i nepotpuni su elementi saopštenja, utoliko vi$\overline{\text { se }}$ što je i preko indikacije za prošireni pojam ${ }^{2}$ (ovde komedija dell'arte), kome se pristupa preko opšteg pojma - komedija, dolazi samo do uopštenih elemenata koji ni informativno ni koncepciono ne upotpunjavaju izgled tog saopštenja, što znači da nema punog saopštenja i potrebna sistematičnost nije jasno došla do izražaja.

Medjutim, za isto saopštenje vidho pozitivnija sistematičnost zapaža se u starijem rečniku ${ }^{3}$, gde osnovni prilog iskazuje pojam - okosnica (kanovačo) skladno sa njegovim punim saopštenjem u proširenom prilogu. Pri takvoj povezanosti osnovni prilog ne mora da iscrpi sve svojstvenosti pojma jer su u njemu spontano izražene tematske indikacije za put na prošireni prilog. U ovom slučaju, prošireni prilog je posebno zadovoljavajući, tj. pruža nam potpuno jedinstvo elemenata, a time i jasnoću i celinu pojma: "Commedia dell'arte coltivata dalle compagnie comiche sin nel secolo $16^{\circ}$, e nei seguenti, detta anche a soggetto, di canovaccio, cioè scenario con le maschere e tipi fissi, che si propone di una tesi morale e sociale".

U ovakvom saopštenju je zaista postignut taj toliko važan sistem razvoja prožet koncepcionim bitnostima, što se ovde jasno vidi, jer pored elementa "maschera" tu je i elemenat "tipa" koji je iz renesansne komedije, a ovde je postao prošireni tip, stalni tip - "tipo fisso", koji zatim proširujući svoju ulogu postaje "maschera".

Nema sumnje da se ovakvo puno saopštenje, u vrlo uspelom toku sistematičnosti, koje istovremeno ukazuje i na ulogu ovog književnog roda, može uvek maksimalno koristiti.

U drugim rečnicima za ovaj isti pojam nije sprovedena ovako potrebna povezanost elemenata canovaccio - c. dell'arte-. ${ }^{4}$ Ako pogledamo i sledeći osnovni prilog: "Trama scritta di un lavoro teatrale il cui sviluppo rimanga affidato al talento d'improvisazione degli attori: tipica della commedia dell'arte ${ }^{\prime \prime}, 5$ bio bi dovoljan kad bi postojala moguénost povezivanja sa komedijom dell'arte, na koju se poziva. Medjutim o tom širem pojmu, komediji dell'arte nema nigde ni pomena, čak ni u opštem pojmu tj. u samom nazivu komedija. Ovo bi bio primer, kao što smo napomenuli, kako se lako izgubi glavna nit prenosnog mehanizma upotpunjavanja elemenata, što je upravo šteta, jer osiromašuje saopštenja.

Takav bi, u principu, bio i postupak pri praćenju i drugih saopštenja u kojima se oseća potreba povezivanja srodnih elemenata, tj. mogućnost praćenja pomenute razvojne linije. 
Ako bismo hteli, npr., da saznamo iz osnovnog priloga ili (preko uputa - odrednica) iz srođhog tj. proširenog priloga sažetu ali dovoljnu informaciju o poetskoj struji Dolce stil nuovo, primili bismo parcijalna ili potpunija saopštenja (zavisno i od sopstvene, individualne dopune, ako se radi o stručnjaku), jer kod saopštenja književnih pojmova uvek osećamo izvesnu potrebu za pribiranjem elemenata po nekoj razvojnoj liniji. Medjutim, ako te linije nema, ili ako su mogućnosti za povezivanje srodnih niti prekinute ili nedovoljne, mora se izgubiti jasna slika tretiranog pojma, ili više pojmova.

Tako sledi, npr., jedno saopštenje da se lirika Slatkog stila ili stilnovistička razlikuje od prethodne lirike -"per schiettezza d'ispirazione, freschezza di sentimento, originalità ..."r6 - sasvim je pojmljivo da bi neko hteo da sazna koja je to prethodna lirika, pod kojim imenom da je potraži, jer su nedorečene njene karakteristike $u$ takvom saopštenju koje nema ni osnovnu bazu za eventualno uporedjivanje različitih elemenata jedne pomenute poezije i druge "prethodne" koja se pretpostavlja kao različita tj. suprotna. I upravo je tako, čim nema te nužne povezanosti, tog znalačkog nijansiranja kontinuiranih niti (ovde, npr., Sicilijansǩe škole i Dolče stila) makar sve samo nagovešteno, gubi mnogo i informativni i opisni i koncepcioni aspekt, dakle sve one komponente koje saopštenje čine u potpunosti korisnim.

Da se dobije saopštenje o Sicilijanskoj školi koja prethodi poetskoj struji Dolce stil valja tragati preko izraza "siciliano". Medjutim, i to saopštenje ne sadrži komponente karakteristiëne za taj pesnički pravac a suprotne napomenutom pravcu koji sledi, dakle ne pruža nikakve mogućnosti uporedjivanja, a onda i napomena - "razlikuje se od prethodne lirike" - nema svog opravdanja, blokira mogućnost dopune srodnih elemenata (jer oni u ovoj književnoj interpretaciji nisu u saglasnosti) i gubi celinu koncepcije.

U drugom rečniku7 medjutim, pod pojmom "stilnovismo" srećno je postavljen informativni deo teme već u osnovnom prilogu ali u spoju sa izvesnom opisnom odrednicom koja upućuje na Stil novo i odmah nagoveštava neke karakteristike te poezije: "Il complesso di temi concettuali e di elementi stilistici che caratterizzano lo stile novo. Estens. L'adesione a certi caratteri propri dello stil novo (spec. per la concezione della donna e dell' amore) da parte di un poeta". Vidimo da je ovde saopštenje uspelo samo zato što sadrži opisnu odrednicu za Stil novo. Medjutim, uz saopštenje pod Stil novo dodat je naziv u zagradi "anche dolce stil novo", a svakako bi bilo preglednije $i$ dostupnije da (ako se ne upućuje i sa Dolce stil nuovo - novo na Stil novo) postoje separatne obostrane prave odrednice. Onda bi se lakše došlo, do traženog punog saopštenja, koje je ovde u skladu sa osnovnim prilogom, pa je jasno i u informativnom i u koncepcionom pogledu, šta više, $u$ njemu se ističu bitni tematski elementi, pa i one suštinske doktrinarne karakteristike stilnovističke poezije: "L'identificazione della nobiltà con la virtù e dell' amore con la nobiltà $(. . .)^{\prime \prime}$.

Upravo bismo istakli da, iako nije lako uspostaviti $i$ odrediti te veze pojmova, da bez mogućnosti praćenja tematske linije, saopštenja veoma malo koriste, a mogu i da nas potpuno udalje od pravog smisla. Naročito je teško ako treba da 
dobijemo saopštenje o nekom kompleksnijem pojmu, kao što bi, npr., bila književnost XVII veka, književnost Seičenta, koju bi valjalo sagledati u sklopu umetničko kulturnih i društvenih pravaca i manifestacija tog doba. Književnost seičenta sadrži varijantu nazvanu Sežentizam čiji je izraz i marinizam, dok je barok okvir i dominantan stil doba. Sve te komponente valja povezati za potpuni izgled književnosti XVII veka, jer svaki pojam, iako separatno definisan ili objašnjen, posredno ili neposredno zadobija elemente drugog srodnog pojma; teško ih je razdvojiti $i$ još teže odabrati kome dati prednost. Tako u književnom pogledu izgleda da su ovi naši rečnici dali prednost baš sečentizmu. Preko saopštenja: "La letteratura del Seicento (V. Secentismo)" 8 ne možemo biti potpuno već samo parcijalno obavešteni, jer sečentismo je samo jedna struja, jedan vid književnosti Seičenta. A ako propratimo ovu odrednicu (V. Secentismo), onda potvrdjujemo to isto, tj. da nije definisana književnost XVII veka (seičenta) već samo sečentizma, utoliko se više to zapaža što je taj manijerizam odmah identifikovan sa marinizmom; "Prese il nome di marinismo". Ako podjemo dalje po liniji povezivanja, onda primećujemo da je pod pojmom marinizam izražen ceo književni pravac doba: "Corrente letteraria propria del XVIT".

Medjutim, očigledno je da valja predstaviti ili označiti i književnost koja ne pripada marinizmu.

U drugom rečniku ${ }^{9}$ okarakterisan je sečentizam opet kao termin koji označava bitne vidove umetnosti, kulture i ukusa doba. Izgleda da se tu misli na opšti barokni okvir, a po elementima koje navodi i književnost, inače jedva nagoveštena, opet se svodi na pojam marinizma, koji je samo: "Il gusto letterario". Inače od pojedinačnih pojmova, svaki za sebe je uglavnom interesantan i kao informacija dovoljan, izuzev integrazionog književnog aspekta, koji je apsolutno ograničen.

Ako bismo još po negde (uvek isti tip rečnika) tragali za saopštenjem o pomenutom pojmu, interesantno je prići starijem rečniku, ${ }^{9}$ u kome se sečentizam, kao vid književnog manijerizma, odmah svodi na uži pojam tj. na poeziju, i tako se, uz tipične elemente, taj, inače pravi smisao, bar sistematičnije lokalizuje.

Ne možemo saznati ništa o takozvanom periodu - Arkadija, ni koja joj je namena, ni funkcija $u$ književnosti. Saopštenje se gubi već $u$ osnovnom prilogu $i$ nema nikakvih mogućnosti za povezivanje sa ikakvim srodnim pojmom. To ipak iznenadjuje, jer ako se toliko saopštava o marinizmu, valja bar samo nagovestiti suprotnu struju.

I o književnom pravcu - Verizam, ne postoji preciznija definicija. Ako neko želi da sazna pravo značenje verizma, onda dobije saopštenje da je to izvestan realizam, izvestan naturalizam. Naidje se i na sledeću definiciju: "Verismo Realismo più forte nelle arti". $10 \mathrm{U}$ svim postojećim rečnicima nije data prava karakteristika tog književnog pravca. Previše se uopštava striktna analogija sa Zolinim naturalizmom, nema izraza za specifičnost, tj. za italijanski aspekt tog pravca, pa je najčešće saopštenje nedovoljno i u informativnom i u koncep- 
cionom pogledu. Nema dopunskih odrednica, tj. odrednica za srodna obaveštenja (npr., V. G. Verga ili sl.). Tako, uglavnom preovladjuje saopštenje: "Verismo corrente letteraria analoga al naturalismo francese $(\ldots)^{\mathbf{1 1}}$ Pri svemu što se nalazi o tom pojmu u raznim rečnicima, verovatno kao najpotpunije obaveštenje, u kome se održava izvesna srećnija povezanost izmedju stranog uticaja i lokalne inspiracije, bilo bi sledeće: "Corrente letteraria dell' Ottocento italiano (...) nata $\mathrm{da}$, una diffusa reazione realistica all'idealismo del tardo romanticismo, in corrispondenza con naturalismo francese, di cui accolse, in via teorica, le istanze sociali e l'esigenza di una narrazione rigorosamente oggettiva, questa tendenza produsse una molteplice e varia narrativa ambientata in un mondo contadino o provinciale, rappresentato nei suoi problemi e sentimenti nelle sue forti tradizioni ecc.". ${ }^{12} \mathrm{Na}$ sličnu pojavu nailazimo i pri konsultovanju još nekih književnih rodova.

Melodrama i pastorala, npr., kao književni rod skoro nemaju nikakve definicije. Melodrama uopšte nema prave i potpune namene, već je objašnjena sa vrlo parcijalnim elementima, a uglavnom kao muzički prikaz: "Testo teatrale destinato totalmente o parzialmente ad essere messo in musica"13 Nema karakterističnih elemenata za rod melodramu, za njen elemenat teksta, za ulogu recitativa ili neke vrste hora, za uloge koje ponekad imaju namenski karakter humorističko-satirički, aluzije na neke društvene pojave itd.

Po jednoj liniji, iako nepotpunih postojećih odrednica, nazreće se melodrama kao književni rod uz slično saopštenje: "Drama con accompagnamento di musica $(\ldots)^{14}$, samo po tome što pruža mogućnost srodnog (iako ne lako dostupnog) povezivanja sa melologo, što spontano upotpunjava definiciju književnog roda, koji je kao takav u upotrebi i adekvatnoj nameni u književnosti i van Italije.

Saopštenja za pastoralu kao književni rod su isto vrlo nepotpuna, siromašna ili skoro ne postoje, sem veoma uopšteno. - "Poesia pastorale che si finge composta da pastori"; 15 "Poesia pastorale che si immagina in un ambiente ideale di pastori"; 16 "Composizione musicale di carattere ingenuo, idillico (..)". ${ }^{17}$

I tako nepotpuna obaveštenja za ovaj idiličan poetsko-lirski rod nailazimo, uglavnom, u svim ovakvim rečnicima. Primećujemo, medjutim, da su ovi više manje tipični italijanski književni rodovi podražavani u književnostima drugih zemalja, dobili odredjenije definicije uz njihovu punu namenu $i$, razume se, uz srodne nove ambijentalne elemente.

Prema tome, izgleda da je veoma problematično predati se brzom proveravanju nekih književnih pojmova, kroz ove najdostupnije, uvek pri ruci, enciklopedijske italijanske rečnike, no valja se radije obratiti, pa i za običnija saopštenja ili samo definicije, na veće enciklopedije i originalne izvore.

\section{Note}

1 Dizionario enciclopedico universale, Sansoni, Firenze. 
Isto, - c. d'arte - c. italiana con maschere, in cui l'attore improvvisava sulla guida di uno scenario o canovaccio formito dall' autore; dal sec. XVI fino al Goldoni che ad essa si oppose.

N. Zingarelli, Vocabolario della lingua italiana, Edizione minore.

4 Palazzi, Novissimo Dizionario della lingua italiana, i dr.

5 G. Devoto, Dizionario della lingua italiana, Le monnier - Firenze.

6

Sansoni, op. cit.

7

8

G. Devoto, op. cit.

Sansoni, op. cit.

9 Devoto, op. cit.

10 Zingarelli, op. cit.

11 Sansoni, op. cit.

12

13

G. Devoto, op. cit.

3 Isto.

14 Sansoni, op. cit.

15 Zingarelli, op. cit.

16

17 Devoto, op. cit.

Riassunto

\section{PROBLEMATICA DI COMUNICAZIONI LETTERARIE NEI PICCOLI VOCABOLARI ENCICLOPEDICI}

L'autore si propone di esaminare certi modi in cui vengono comunicate alcune espressioni letterarie nei piccoli dizionari enciclopedici, esponendovi una sistematica analisi di elementi occorrenti a rendere la comunicazione letteraria più valida e più completa.

In tal senso viene suggerito un possibile collegamento di elementi affini, miranti a offrirci una certe continuità del tema desiderato sia nel senso informativo che concettuale.

Da questo punto di vista vengono prese in considerazione certe espressioni letterarie, correnti o generi (ad esempio: canovaccio - commedia dell'arte, dolce stil novo - nuovo, seicento - secentismo, marinismo, arcadia, verismo, melodramma, dramma pastorale) con adeguate analisi per una più espressiva e più effettiva comunicazione letteraria. 